\section{Определение числа постов по ремонту агрегатов машин на предприятиях технического сервиса}

\author{
А. В. Питухин ${ }^{1}$ \\ Н. И. Серебрянский \\ В. Н. Шиловский \\ Петрозаводский государственный университет
}

\section{АННОТАЦИЯ}

В статье изложена методика определения оптимального числа постов по ремонту агрегатов машин на основе минимизации суммарных экономических потерь от простоя постов и отказов на поступившие заявки.
\end{abstract}

Ключевые слова: отказ, вероятность отказа, пункт технического сервиса, пост обслуживания, обоснование числа постов.

\section{SUMMARY}

This paper is aimed at methods of optimal number defining of servicing posts for machine aggregates repairing on the basis of the minimization of total cost expenses due to posts downtime and refusal to carry out bookings.

Keywords: failure, probability of failure, servicing center, determination of a number of servicing posts.

При плановой экономике автотракторная техника эксплуатировалась, в основном, в условиях государственных (унитарных) предприятий или коллективных хозяйств. Каждое предприятие имело десятки и даже сотни единиц техники, капитальный ремонт которой, в том числе в виде узлов и агрегатов, планировался в соответствии с утвержденными нормами амортизационных отчислений или ресурсными характеристиками объектов ремонта. В этих условиях ремонтное предприятие могло быть равномерно загружено в течение года на всех технологических участках. При определении параметров такого предприятия все расчеты выполнялись детерминированным методом по плановой трудоемкости работ и фонду рабочего времени.

В условиях рыночной экономики ситуация изменилась. Автотракторная техника стала эксплуатироваться на предприятиях и в фирмах различных форм собственности и типоразмеров, в которых производство ремонтных работ не стало подвергаться былой плановой регламентации, в том числе и из-за устаревания ранее действовавшей и отсутствия новой научнотехнической и нормативной документации (НТД). Работоспособное состояние техники поддерживается, чаще всего, устранением возникших в процессе эксплуатации отказов в форме текущего ремонта, включая и замены достигших предельного состояния узлов

\footnotetext{
${ }^{1}$ Авторы - соответственно профессор, доцент, профессор кафедры технологии металлов и ремонта (c) А. В. Питухин, Н. И. Серебрянский, В. Н. Шиловский, 2003
}

и агрегатов, капитальный ремонт которых также носит случайный, а не плановый характер и выполняется как на предприятиях, эксплуатирующих технику, так и на специализированных ремонтных предприятиях и в пунктах технического сервиса (ПТС).

При случайной, а не плановой загрузке ПТС в потоке заявок имеют место сгущения и разряжения. Сгущения приводят либо к отказу в обслуживании, либо к образованию очереди. Разряжения приводят к непроизводительному (убыточному) простою отдельных постов, стендов или зоны ремонта в целом. Предприятие технического сервиса машин становится типичной системой массового обслуживания (СМО) открытого или закрытого типа.

Для таких систем существует методика решения задачи анализа функционирования станций технического обслуживания техники с определением среднестатистических параметров их работы. Однако, наряду с задачей анализа, для систем массового обслуживания не менее важна и актуальна задача синтеза, которая заключается в определении оптимального числа постов на предприятиях технического сервиса по результатам оценки статистических характеристик потока заявок на восстановление отказавших объектов.

При оптимальном числе постов (далее под постами следует понимать и стенды для ремонта агрегатов) экономические потери (возможные убытки), как от непроизводительного простоя постов, так и в следствие отказов от исполнения поступивших заявок, будут иметь минимальные значения.

Таким образом, условие выбора оптимального числа постов имеет вид:

$$
W\left(N_{i}^{*}\right)=\min W\left(N_{I}\right),
$$

где $N_{i}^{*}$ - оптимальное число постов (или стендов) і-го наименования, соответствующее минимуму суммарных экономических потерь от простоя постов и отказов от выполнения заявок, руб.;

$W\left(N_{I}\right)$ - суммарные экономические потери от простоя постов (или стендов) і-го наименования и отказов от выполнения заявок, руб.

Функция оптимизации отражает количественное значение суммарных экономических потерь (или упущенной выгоды) и в общем случае имеет вид

$$
W\left(N_{I}\right)=C_{1} \cdot \lambda_{i} \cdot P_{\text {omк }}+C_{2}\left[N_{i}-M\left(K_{i}\right)\right],
$$

где $C_{1}$ - средняя прибыль предприятия от обслуживания одной заявки на посту-стенде i-го наименования, руб.;

$C_{2}$ - экономические потери от простоя одного постастенда і-го наименования, руб.;

$\lambda_{i}$ - параметр потока заявок (среднее число заявок і-го наименования в единицу времени); 
$P_{\text {отк }}$ - вероятность отказа заявке і-го наименования;

$M(K)$ - математическое ожидание числа заявок постов-стендов і-го наименования;

$N_{i}$ - количество постов-стендов і-го наименования.

При поиске оптимального (минимального) значения функции варьируем числом постов-стендов $N_{i}$. Неуправляемыми переменными, и в то же время неизвестными величинами, определяемыми расчетным путем по экспериментальным материалам, являются вероятность отказа заявке и математическое ожидание числа занятых постов-стендов.

Рассмотрим методику определения вероятности отказа заявке и математического ожидания числа занятых постов-стендов для СМО открытого типа, функционирующей с ожиданием в очереди при ограничении ее длины. Пусть ПТС имеет n постов-стендов для ремонта коробок передач и $\mathrm{m}$ мест ожидания очереди на их ремонт. В этом случае $P_{\text {отк }}=P_{n+m}$, то есть заявка получает отказ, когда на ремонт поступает коробка передач при занятых $\mathrm{n}$ постах и $\mathrm{m}$ местах в очереди на ремонт.

Значения $P_{\text {отк }}$ и $M\left(K_{i}\right)$ рассчитываются аналитическим методом по формулам [2]:

$$
\begin{aligned}
& P_{\text {omк }}=\frac{U^{n+m}}{n ! \cdot n^{m}} \cdot P_{0} ; \\
& M(K)=\sum_{K=0}^{n} K \cdot \frac{U^{K}}{K !} \cdot P_{0}+\sum_{K=n+1}^{n+m} n \cdot \frac{U^{K}}{n ! n^{K-n}} \cdot P_{0},
\end{aligned}
$$

где $P_{0}$ - вероятность того, что все посты-стенды свободны;

$K$ - количество занятых постов-стендов и мест в очереди на ремонт;

$U$ - параметр загрузки системы,

$$
U=\lambda \cdot T_{c p},
$$

где $T_{c p}$ - среднее время обслуживания одной заявки, час.

Вероятность того, что все посты-стенды по ремонту коробок передач свободны, определяется по формуле [3]:

$$
P_{0}=\frac{1}{\sum_{K=0}^{n} \frac{U^{K}}{K !}+\sum_{K=n+1}^{n+m} \frac{U^{K}}{n ! n^{K-n}}}
$$

Интенсивность потока отказов, необходимая для решения задачи по оптимизации числа постов предприятия технического сервиса, определяется количеством и техническим состоянием обслуживаемых объектов. При установившемся потоке ресурсных отказов восстанавливаемых объектов их количество становится неизменным. Качественно система (парк) объектов постоянно и неравномерно во времени обновляется. В любой момент времени одновременно эксплуатируются объекты с различной наработкой, следовательно, с различной вероятностью отказа. Техническое состояние парка объектов оценивается вероятностью отказа на определенном интервале эксплуатации $\left(q_{n}\right)$, которая определяется по формуле [3 ]:

$$
q_{n}=F_{n}-\sum_{i=1}^{n-1} q_{i} \cdot\left(F_{n}-F_{n-i}\right),
$$

где $F_{n}$ - вероятность отказа единичного объекта при наработке L, равной сумме первых n интервалов, определенная без учета замен.

Задача определения оптимального числа постов решается при установившемся количественно, но изменяющемся качественно парке восстанавливаемых объектов, когда $q_{n}$ стабилизируется и принимает определенное значение. Рассмотрим пример расчета средневзвешенной вероятности отказа на любом интервале наработки при установившемся численном парке восстанавливаемых объектов. По условию примера при проведении испытаний трелевочных тракторов по плану NUN получены следующие показатели долговечности коробок передач:

- $\quad$ средний ресурс $\mathrm{L}_{\mathrm{cp}}=5290$ моточасов,

- среднее квадратическое отклонение среднего peсурса $\sigma_{L}=1116$ моточасов.

Распределение ресурса соответствует закону Вейбулла. Рассматривается парк тракторов за период эксплуатации 24000 моточасов, включающий 24 интервала по 1000 моточасов каждый. Расчет выполнен на ЭВМ с применением программы, составленной на кафедре технологии металлов и ремонта ПетрГУ. По алгоритму программы рассчитывается функция распределения $\mathrm{F}(\mathrm{L})$, плотность распределения $\mathrm{f}(\mathrm{L})$ наработки на отказ без замен и по формуле (7) - вероятность ресурсного отказа коробок передач на конец каждого интервала. Результаты расчетов представлены на рис. 1.

Из рис. 1 видно, что средневзвешенная вероятность ресурсного отказа коробки передач стабилизируется с небольшими колебаниями на конец десятого интервала, на 10000 моточасов эксплуатации парка объектов и принимает значение $q_{y c m}=0,17 \ldots 0,18$. Это значение можно принять в расчет количества ресурсных отказов коробки передач на интервале при эксплуатации $\mathrm{N}$ тракторов.

$$
M=q_{y c m} \cdot N
$$

где $M$ - количество ресурсных отказов на принятом интервале. 
Рассмотрим пример расчета оптимального числа стендов по ремонту коробок передач на предприятии технического сервиса. Условия примера: число стендов оптимизируется с учетом поступления на ПТС потока заявок на ремонт КП с интенсивностью $\lambda=1,3$ объекта в час. Среднее время обслуживания одной заявки составляет $T_{c p}=3,2$ часа. Предприятие имеет три места очереди $(\mathrm{m}=3)$. Прибыль предприятия от обслуживания одной заявки $C_{l}=300$ рублей. Экономические потери от простоя одного поста $C_{2}=50$ рублей. Расчет выполнен на ЭВМ с применением программы, составленной на кафедре технологии металлов и ремонта. Результаты расчетов приведены на графиках зависимости экономических потерь от числа постов (рис. 2).

Анализ результатов расчетов показывает, что при принятых по условию примера данных предприятие имело бы минимальные экономические потери при наличии 4-5 стендов для капитального ремонта коробок передач. Это количество стендов можно считать оптимальным при заданном потоке заявок на ремонт КП.

\section{СПИСОК ЛИТЕРАТУРЫ}

1. ГОСТ 27.002-89. Надежность в технике. Основные понятия, термины и определения. М.:Изд-во стандартов, 1991. $27 \mathrm{c}$.

2. Питухин А. В., Шиловский В. Н., Серебрянский Н. И. Применение вероятностно-статистических методов для решения задач по надежности и ремонту машин и оборудования: Учеб. пособие. Петрозаводск: Изд-во ПетрГУ, 1999. 146 с.

3. Питухин А. В., Шиловский В. Н., Серебрянский Н. И. Оценка среднего числа отказов и вероятности их появления для восстанавливаемых объектов на основе закона распределения наработки до первого отказа // Труды лесоинженерного факультета ПетрГУ. Вып. 3. Петрозаводск, 2001. c. $80-82$.

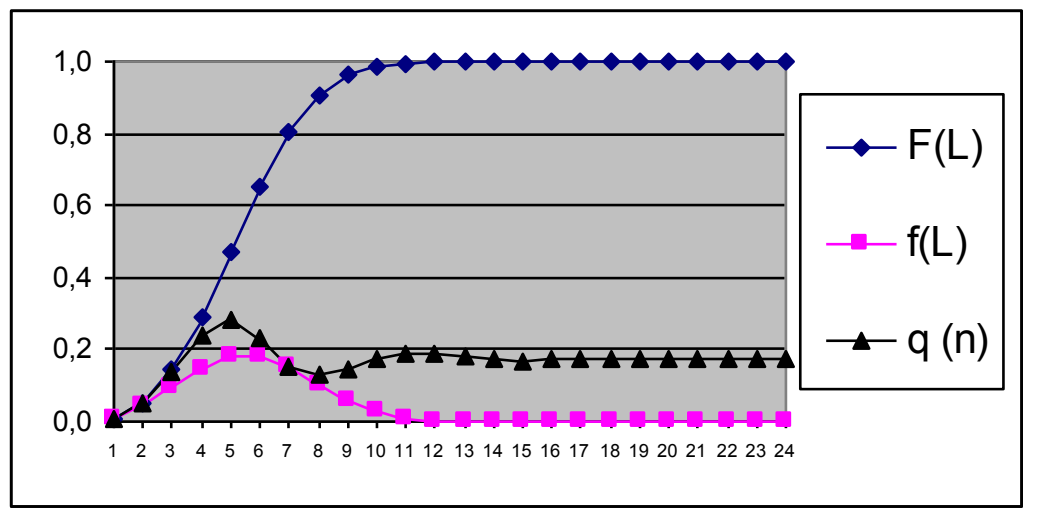

Рис. 1. Расчет средневзвешенной вероятности ресурсного отказа коробок передач

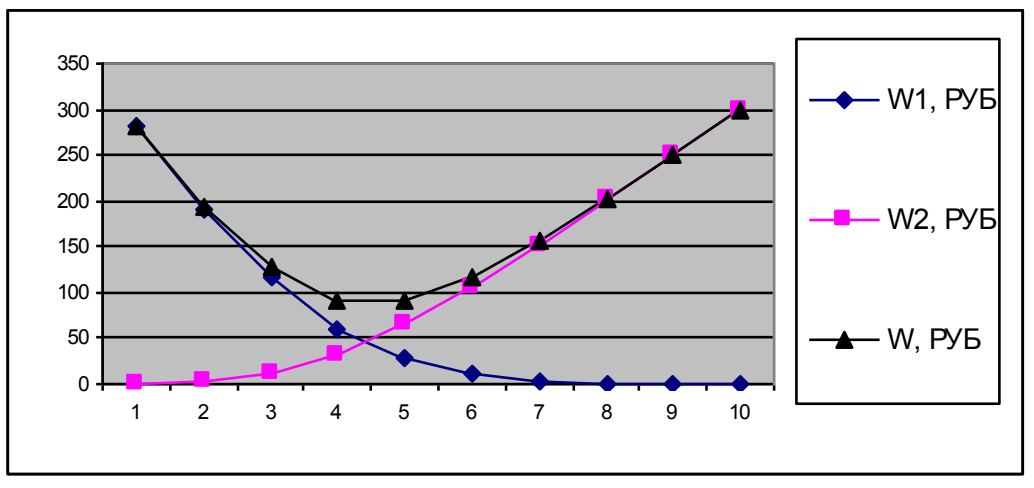

Рис. 2. Зависимость экономических потерь от количества постов по ремонту коробок передач на предприятии:

W1 - экономические потери от простоя объектов ремонта;

W2 - экономические потери от непроизводительного простоя постов; $\mathrm{W}$ - суммарные экономические потери 